\title{
The Best Balance of Oxygen Flow and Deposition Rate to Give Little Absorption of Aluminum Oxide Film Deposited by Electron Beam Evaporation Technique
}

\author{
R. Shakouri ${ }^{1}$ \\ ${ }^{1}$ Department of Physics, Faculty of science, Imam khomeini international university, Qazvin, Iran \\ Correspondence: R. Shakouri, Department of Physics, Faculty of science, Imam khomeini international university, \\ Qazvin, Iran. Tel: 98-281-378-0021/98-281-3780-084. E-mail: shakouri2669@gmail.com
}

Received: March 14, 2014 Accepted: March 26, 2015 Online Published: April 17, 2015

doi:10.5539/apr.v7n3p41 URL: http://dx.doi.org/10.5539/apr.v7n3p41

\begin{abstract}
The effects of deposition rate and oxygen flow rate on refractive index of aluminum oxide film are investigated. The $\mathrm{Al}_{2} \mathrm{O}_{3}$ films are deposited by electron beam technique on glass substrate at different deposition rates and oxygen flow rates. Substrate is heated to reach $300^{\circ} \mathrm{C}$ and the temperature is kept constant during the thin film growth. Then, using the maxima and minima of transmittance, the index of refractive and the extinction coefficient of samples has been determined. It has been found that the index of refractive increase if we reduce the oxygen flow while keeping the deposition rate the same. Hardness is also increased with the decrease in the $\mathrm{O}_{2}$ flow rate. At some low oxygen flow, the extinction coefficient is small and therefore the $\mathrm{Al}_{2} \mathrm{O}_{3}$ films have some absorption.
\end{abstract}

Keywords: aluminum oxide film, deposition rate, oxygen flow rate, index of refraction

\section{Introduction}

Aluminum oxide $\left(\mathrm{Al}_{2} \mathrm{O}_{3}\right)$ is an ordinarily used intermediate index material. It is used to produce optical thin film coatings. This material has been applied as a protective coating (Ciliberto, Fragala, Rizza, Spoto, \& Allen, 1995) because it has high resistance to corrosion. Also, it is an important material for temperature stabilization and as passivation layers in metal-oxide-semiconductor (MOS) devices (Pande, Nair, \& Gutierrez, 1983; Vuoristo, Mäntylä, Kettunen, \& Lappalainen, 1991; Jakschik, Avellan, Schroeder, \& Bartha, 2004). Aluminum oxide thin films have been deposited by various techniques, including magnetron sputtering (Ha, Choo, \& Im, 2002; Segda, Jacquet, \& Besse, 2001; Khanna, Bhat, Harris, \& Beake, 2006; Fietzke, Goedicke, \& Hempel, 1996), electron beam evaporation (Zywitzki, Goedicke, \& Morgner, 2002; Patil, Bendale, Puri, \& Puri, 1996), plasma enhanced chemical vapor deposition (Lin, Wang, \& Hon, 1996), filtered cathodic vacuum arc (FCVA) (Zhao, Tay, Lau, \& Xiao, 2003), spray pyrolysis (Aguilar-Frutis, Garcia, Falcony, Plesch, \& Jimenez-Sandoval, 2001), etc.

Films produced by these techniques in different laboratories have different refractive indexes. This is because different deposition techniques to cause different film structures. At the design of multi-layer coatings, it is necessary to know the index of refraction and dispersion for materials. Generally, the index of refraction is a complex quantity, $N=n-i k$. Here, the $n$ is the index of refraction for a purely dielectric material and the $k$ is extinction coefficient that describes absorption in a material. The absorption coefficient $\alpha$ is defined as $\alpha=4 \pi k / \lambda$, where $\lambda$ is the wavelength. The ratio of the transmitted intensity to the initial intensity through an absorbing medium of thickness $t$ can be found by $I / I_{0}=e^{-\alpha t}$. Moreover, any material must be having a good density layer for higher index and as little as possible absorption. Thin films rarely have the same refractive index as similar bulk materials. The main reason for this is their microstructure that is rarely bulk-like but usually shows a columnar morphology. The most unfortunate features of the columnar microstructure are the pore shaped voids between the columns. They are the main reason in reducing film density, and affect the optical properties. There are a varied number of papers in journals on the determination of index of refraction (Nilsson, 1968; McPhedran, Botten, McKenzie, \& Netterfield, 1984; Minkov, 1991).

In this paper, we have investigated the influence of the deposition rate and oxygen flow rate on refractive index of aluminum oxide film. We have prepared the aluminum oxide films by electron beam evaporation on glass substrate and depositions have been carried out at different deposition rates and oxygen flow rates. The 
transmittance spectrum of samples is recorded. This produces a transmittance spectrum with a few peaks. We collect the wavelength and magnitude of the maxima and minima of transmittance and then the index of refractive and the extinction coefficient of samples have been determined by "Essential Macleod" (Thin Film Center Inc., 2015). Variations of the refractive index, the extinction coefficient and hardness of $\mathrm{Al}_{2} \mathrm{O}_{3}$ films have been studied as a function of the oxygen flow rate. The relationship among the $\mathrm{O}_{2}$ flow, the extinction coefficient and the refractive index of the films was investigated for films oxide (Jerman, Qiao, \& Mergel, 2005). The question now arises what the best deposition rate and the $\mathrm{O}_{2}$ flow is. Motivation of this study is to find the best balance of oxygen flow and deposition rate to give little absorption and good density for higher index.

\section{Experimental Detail}

Aluminum oxide thin films have been deposited by reactive electron beam evaporation technique. Electron beam source is an E-gun in $10 \mathrm{KV}, 5 \mathrm{KW}$, and 270 deg bent- beam. The vacuum system consists of a diffusion pump that is backed with a rotary pump. These pumps are prepared the chamber to $10^{-6}$ Torr the region. Aluminum oxide is placed on water cooled copper crucible and a glass is used as substrate. The $\mathrm{Al}_{2} \mathrm{O}_{3}$ tablets (Merck) are used as the evaporation material. The distance between the substrate and the source is $50 \mathrm{~cm}$. As is common with all materials, increased substrate temperature leads to higher density. Therefore substrate is heated by quartz heater to reach $300^{\circ} \mathrm{C}$ and the temperature is held constant during the thin film growth. This temperature is the highest value that our vacuum system can provide. Our E-gun has a few of sweep patterns. To minimize the influence distribution of the evaporating material, we use the same sweep for all samples.

The index of refractive of samples has been determined by "Essential Macleod" (Thin Film Center Inc., 2015). The technique used is of the class known as envelope methods. The technique is based on the Manifacier paper (Manifacier, Gasiot, \& Fillard, 1976) but it goes beyond that to include inhomogeneity in the layers. Such methods focus on the maxima and minima of reflectance or transmittance and the first stage of the calculation involves the interpolation of the maxima and minima to generate the envelopes. When the layer is absorbing, the maxima and minima depart from these ideal envelopes by an amount that increases with thickness but, when absorption is not too high, the envelopes can still serve to launch the $n$ and $k$ calculations. For the $\mathrm{Al}_{2} \mathrm{O}_{3}$ films, absorption is not too high. The film thickness must be such that there are extrema within wavelength range of interest. We record the transmittance spectrum of samples over the region of 400-800 nm. The measurement must be taken with an uncoated rear surface and include the multiple reflections generated by the rear surface. This produces a transmittance spectrum with a few peaks. These points are entered as transmittance design goals in the thin film design computer program (Essential Macleod). We then enter the known substrate index (1.52) and an estimate of the coating index. Next, we ask the program to optimize a dispersive index for a best fit to the input data points. Film hardness is determined by nanoindentation technique (Oliver, \& Pharr, 1992).

For the present research, we have deposited a set of alumina films on glass substrate. Depositions have been carried out at different deposition rates and oxygen flow rates but the glass substrate is kept at temperature $300^{\circ} \mathrm{C}$. The deposition rate is monitored by an optical monitoring. Table 1 lists the values deposition rates and oxygen rates.

Table 1. List of samples prepared at different deposition rate and $\mathrm{O}_{2}$ flow $10 \mathrm{SCCM}$

\begin{tabular}{ccc}
\hline Sample No. & $\mathrm{O}_{2}(\mathrm{SCCM})$ & Deposition rate $(A \% s)$ \\
\hline 1 & 10 & 2 \\
2 & 10 & 5 \\
3 & 10 & 8 \\
4 & 25 & 5 \\
5 & 25 & 8 \\
6 & 25 & 2 \\
7 & 40 & 5 \\
8 & 40 & 8 \\
9 & 40 &
\end{tabular}




\section{Results and Discussion}

The transmission spectra of samples were measured by a spectrophotometer. Figure 1 gives the transmittance versus wavelength at the spectral region $400-800 \mathrm{~nm}$ for different oxygen flows while the deposition rate was kept at $8 \mathrm{~A}^{\circ} / \mathrm{s}$. The substrate temperature is $300^{\circ} \mathrm{C}$ and the optical thickness of films is twelve quarter wave at $432 \mathrm{~nm}$ monitoring wavelength. It can be seen, as oxygen flow decrease, minima of transmittance decrease. This means that the refractive index is increased when oxygen flow is decreased. Figure 2 shows $n$ as a function of wavelength for different oxygen flows and the deposition rate $8 A^{\circ} / s$. It can be observed that with the increase in the oxygen flow rate, the refractive index decrease. Zhao, Tay, Lau, and Xiao (2003) has shown that for the $\mathrm{Al}_{2} \mathrm{O}_{3}$ films deposited by FCVA technique, the refractive index of the films decrease as oxygen pressure in the deposition ambient is increased. Figure 3 shows the transmission spectra for different oxygen flow where the deposition rate was held constant at $2 \mathrm{~A}^{\circ} / \mathrm{s}$. Again, it is clear that from curves with the increase of oxygen flow, minima of transmittance decrease and this means that with the increase in the oxygen flows, the refractive index decrease. Figure 4 shows $n$ as a function of wavelength for different oxygen flows and the deposition rate $2 A^{\circ} / s$. Here, it is clear that, the lower oxygen flow, the more will be the refractive index. If we compare Figure 2 with Figure 4, we will find the $10 \mathrm{SCCM}$ at $2 \mathrm{~A}^{\circ} / \mathrm{s}$ has the same index of refraction as the $40 \mathrm{SCCM}$ at the $8 A^{\circ} / \mathrm{s}$; the $\mathrm{O}_{2}$ seems to compete with the $\mathrm{Al}_{2} \mathrm{O}_{3}$ at the substrate for a position, so the ratio of the arrival rate of the $\mathrm{Al}_{2} \mathrm{O}_{3}$ to the $\mathrm{O}_{2}$ at the substrate will determine index of the $\mathrm{Al}_{2} \mathrm{O}_{3}$. This is why the $40 \mathrm{SCCM}$ at $8 A^{\circ} / s$ has the same index of refraction as the $10 \mathrm{SCCM}$ at the $2 A^{\circ} / \mathrm{s}$. In Maiti et al. (2010), NamitaMaiti, et al found that the refractive index increases with increasing $\mathrm{O}_{2}$ flow and they did not mention to the deposition rate. In addition, they observed a sudden decrease for index at 5 SCCM that is strange.

The- $k$ value in Figure 5 shows, as the $\mathrm{O}_{2}$ flow rate decrease to $10 \mathrm{SCCM}$ at the $8 \mathrm{~A}^{\circ} / \mathrm{s}$, the $\mathrm{Al}_{2} \mathrm{O}_{3}$ film has some absorption. Therefore, if we reduce the $\mathrm{O}_{2}$ flow rate while keeping the deposition rate the same, the index will be increased but this result in some absorption. Optical absorption is an important effect for films used in high power laser technology where high absorption can give local failure of the coating. However, the extinction coefficient of the $\mathrm{Al}_{2} \mathrm{O}_{3}$ film is negligible as shown Figure 5. Thus, it is advisable to deposit the $\mathrm{Al}_{2} \mathrm{O}_{3}$ film at high deposition rates and low $\mathrm{O}_{2}$ flow rates. Hardness values are plotted in Figure 6 as the function of the $\mathrm{O}_{2}$ flow rate used during deposition. It can be observed that hardness increase as decreasing the $\mathrm{O}_{2}$ flow rate. As the deposition rate is increased from $2 A^{\circ} / s$ to $8 A^{\circ} / s$, hardness is increased from 12 Gpa to $18 \mathrm{Gpa}$. As a result, the layer density is increased with the decrease in the $\mathrm{O}_{2}$ flow rate.

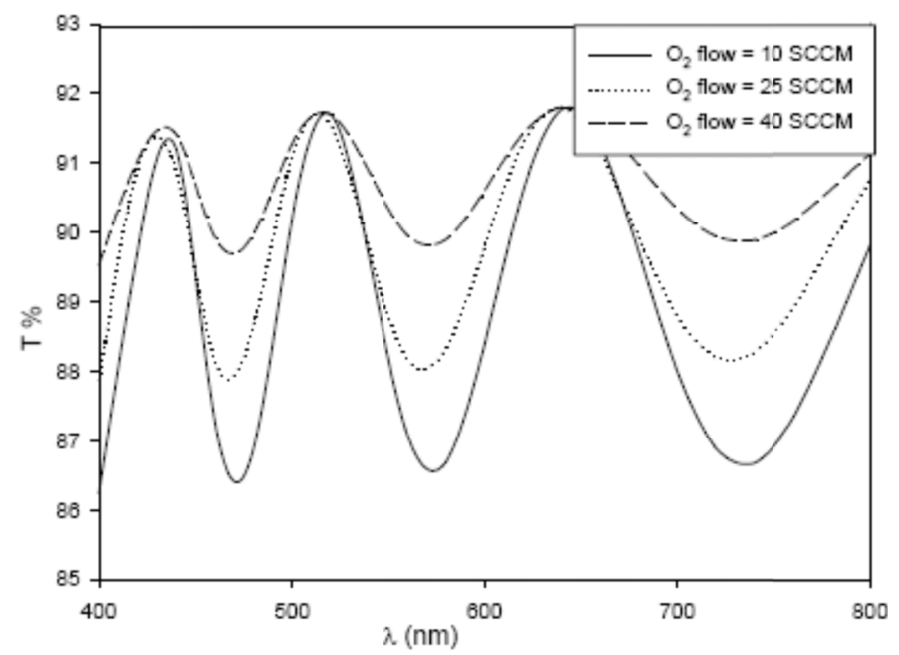

Figure 1. The transmittance versus wavelength for different oxygen flows and the deposition rate $8 \mathrm{~A}^{\circ} / \mathrm{s}$ 


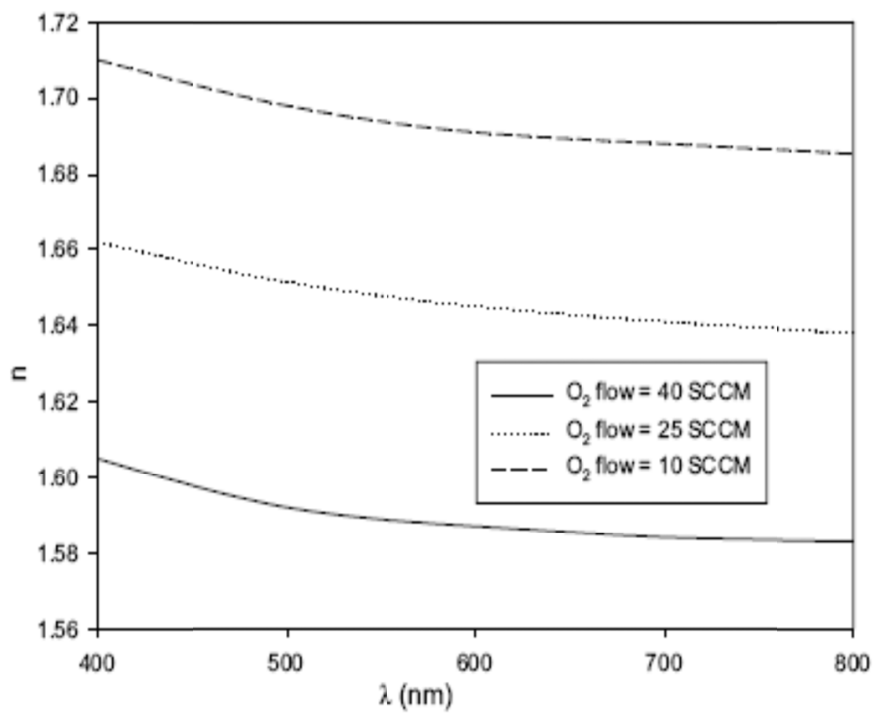

Figure 2. $n$ as a function of wavelength for different oxygen flows and the deposition rate $8 \mathrm{~A}^{\circ} / \mathrm{s}$

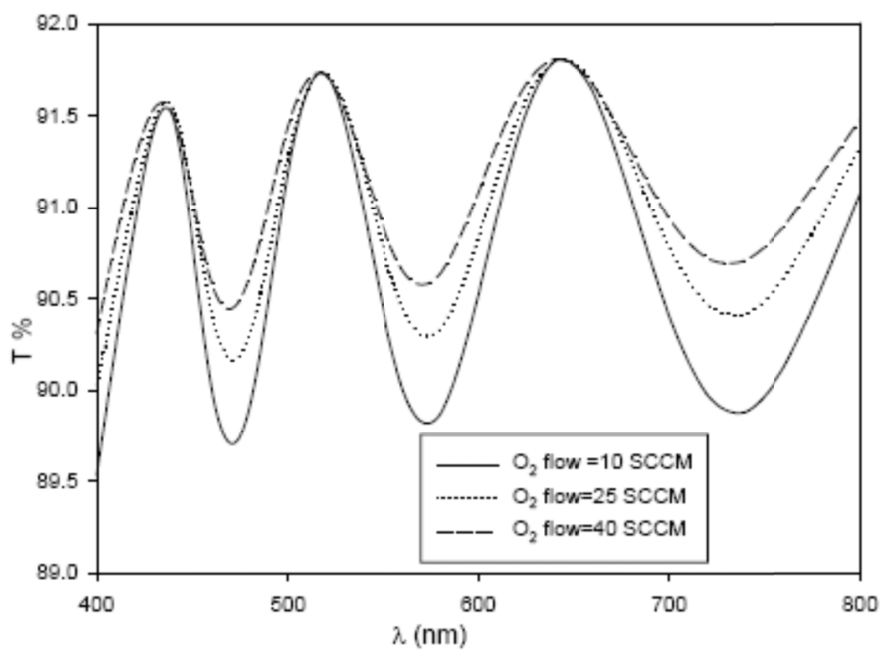

Figure 3. The transmission spectra for different oxygen flows and the deposition rate $2 \mathrm{~A}^{\circ} / \mathrm{s}$

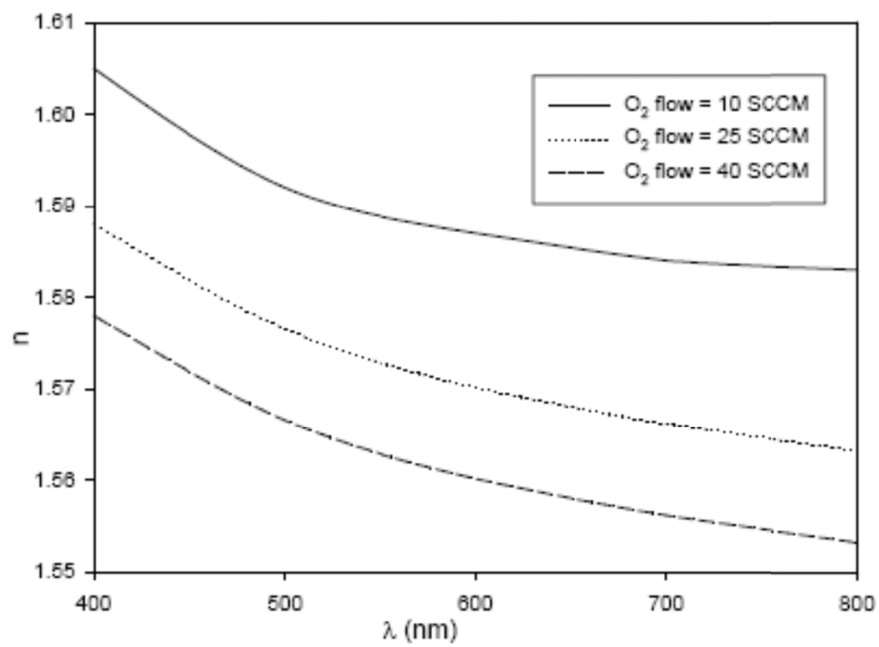

Figure 4. $n$ as a function of wavelength for different oxygen flows and the deposition rate $2 \mathrm{~A}^{\circ} / \mathrm{s}$ 


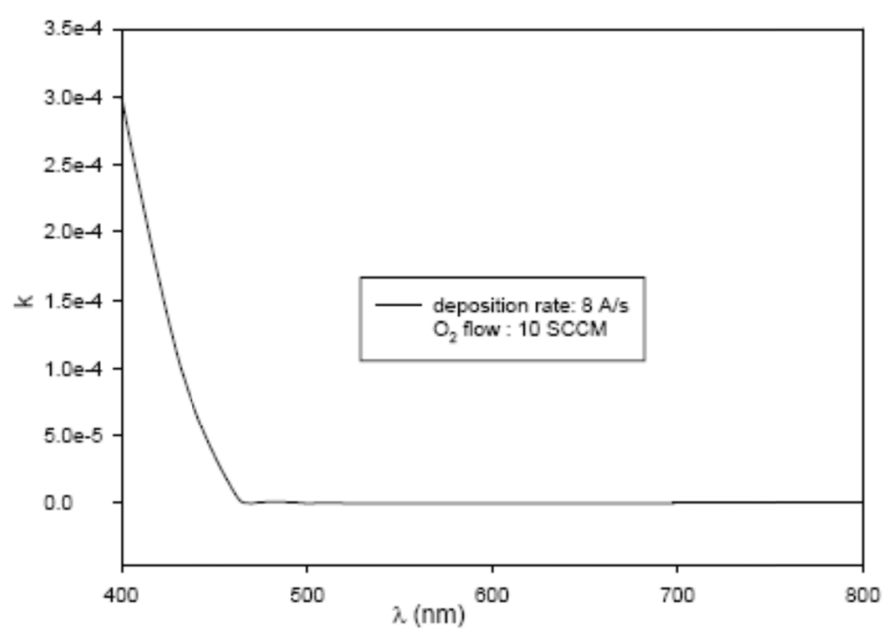

Figure 5. The extinction coefficient as a function of wavelength for $10 \mathrm{SCCM}$ at the $8 \mathrm{~A}^{\circ} / \mathrm{s}$

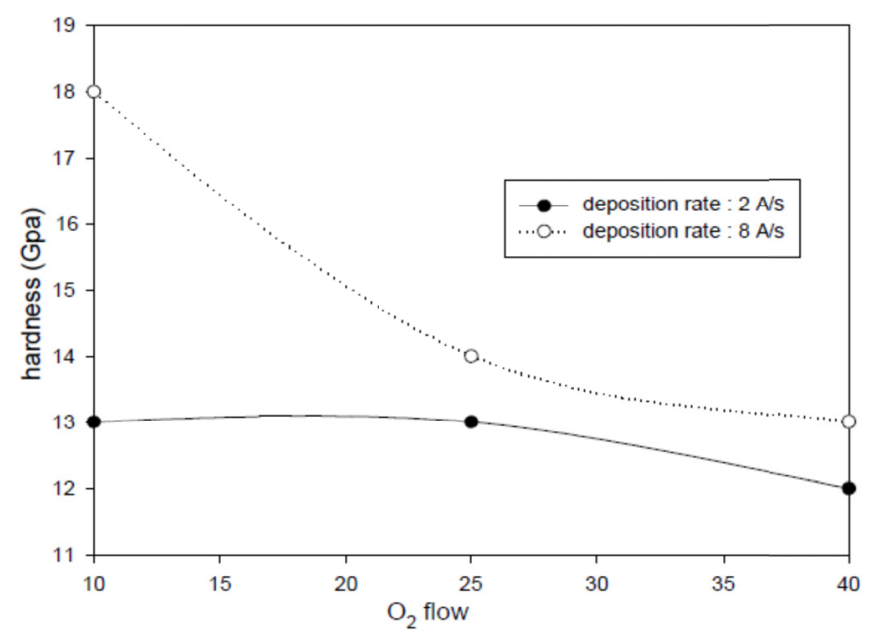

Figure 6. Hardness values as the function of the $\mathrm{O}_{2}$ flow rate

We now explain what the physics behind of our observation of experimental is. The most relevant physical consideration the value of refractive index is its direct relation on the density of thin film. In general, index is higher for more dense films (Cho \& Hwangbo, 1996). On the other hand, the density film depends on energy of deposited atoms or molecules. The mean free path (MFP) is the average distance that a molecule will travel before colliding with another at a given temperature and pressure. The MFP is given by O'Hanlon (2003)

$$
M F P=\frac{5 \times 10^{-3}}{P \text { Torr }} \mathrm{cm}
$$

In Pulker (1984) have been indicated that at $1 / 100$ th of the MFP and at $P=10^{-5}$ Torr we can expect $99 \%$ of the molecules to arrive without a collision but at the MFP only $37 \%$ would have had no collision. This comment result from the Survival Equation

$$
\frac{N}{N_{0}}=\exp \left(-\frac{x}{M F P}\right)
$$

where $N$ is the number of molecules that have not collided after a distance $x$. As the $\mathrm{O}_{2}$ flow increases, the MFP becomes shorter. Thus, the kinetic energy of evaporated particles becomes lower because of collisions with gas molecules. As a result, evaporated particles have less energy for surface diffusion. This is why that the increase of the $\mathrm{O}_{2}$ flow results in lower refractive index. As shown in Figure 5 at some low oxygen flow, the extinction coefficient is not zero and therefore the $\mathrm{Al}_{2} \mathrm{O}_{3}$ films have some absorption. This can be explained as following: 
when the $\mathrm{O}_{2}$ flow is low, not all $\mathrm{Al}$ is oxidized and therefore that part is metal has absorption. Oxygen vacancies can be repaired by adequate oxygen (Zhao, Wang, Gong, Shao, \& Fan, 2003). For the $\mathrm{Al}_{2} \mathrm{O}_{3}$ film the extinction coefficient is very small as shown in Figure 5 and absorption is unimportant.

\section{Conclusion}

The effects of deposition rate and oxygen flow rate on refractive index of aluminum oxide film were examined. When, we reduced the $\mathrm{O}_{2}$ flow rate while keeping the deposition rate the same, the index and hardness increased. This was why deposited molecules at lower $\mathrm{O} 2$ flow had higher surface mobility and could fully diffuse. At some low oxygen flow, The $\mathrm{Al}_{2} \mathrm{O}_{3}$ films had some absorption. This attributed to not oxidize all $\mathrm{Al}$. However, the extinction coefficient of the $\mathrm{Al}_{2} \mathrm{O}_{3}$ film was small. Thus, it is appropriate to deposit the $\mathrm{Al}_{2} \mathrm{O}_{3}$ film at high deposition rates and low $\mathrm{O}_{2}$ flow rates.

\section{Reference}

Aguilar-Frutis, M., Garcia, M., Falcony, C., Plesch, G., \& Jimenez-Sandoval, S. (2001). A study of the dielectric characteristics of aluminum oxide thin films deposited by spray pyrolysis from Al (acac) 3. Thin Solid Films, 389(1), 200-206. http://dx.doi.org/10.1016/S0040-6090(01)00854-9

Cho, H. J., \& Hwangbo, C. K. (1996). Optical inhomogeneity and microstructure of ZrO 2 thin films prepared by ion-assisted deposition. Applied optics, 35(28), 5545-5552. http://dx.doi.org/10.1364/AO.35.005545

Ciliberto, E., Fragala, I., Rizza, R., Spoto, G., \& Allen, G. C. (1995). Synthesis of aluminum oxide thin films: Use of aluminum tris - dipivaloylmethanate as a new low pressure metal organic chemical vapor deposition precursor. Applied physics letters, 67(11), 1624-1626. http://dx.doi.org/10.1063/1.114960

Fietzke, F., Goedicke, K., \& Hempel, W. (1996). The deposition of hard crystalline Al 2 O 3 layers by means of bipolar pulsed magnetron sputtering. Surface and Coatings Technology, 86, 657-663. http://dx.doi.org/10. 1016/S0257-8972(96)03075-7

Ha, W. H., Choo, M. H., \& Im, S. (2002). Electrical properties of Al 2 O 3 film deposited at low temperatures. Journal of non-crystalline solids, 303(1), 78-82. http://dx.doi.org/10.1016/S0022-3093(02)00968-7

Jakschik, S., Avellan, A., Schroeder, U., \& Bartha, J. W. (2004). Influence of Al 2 O 3 dielectrics on the trap-depth profiles in MOS devices investigated by the charge-pumping method. Electron Devices, IEEE Transactions on, 51(12), 2252-2255. http://dx.doi.org/10.1109/TED.2004.839878

Jerman, M., Qiao, Z., \& Mergel, D. (2005). Refractive index of thin films of $\mathrm{SiO} 2, \mathrm{ZrO} 2$, and $\mathrm{HfO} 2$ as a function of the films' mass density. Applied optics, 44(15), 3006-3012. http://dx.doi.org/10.1364/AO.44.003006

Khanna, A., Bhat, D. G., Harris, A., \& Beake, B. D. (2006). Structure-property correlations in aluminum oxide thin films grown by reactive AC magnetron sputtering. Surface and Coatings Technology, 201(3), 1109-1116. http://dx.doi.org/10.1016/j.surfcoat.2006.01.033

Lin, C. H., Wang, H. L., \& Hon, M. H. (1996). The effect of residual stress on the adhesion of PECVD-coated aluminum oxide film on glass. Thin Solid Films, 283(1), 171-174.

Maiti, N., Biswas, A., Tokas, R. B., Bhattacharyya, D., Jha, S. N., Deshpande, U. P., ... \& Das, A. K. (2010). Effects of oxygen flow rate on microstructure and optical properties of aluminum oxide films deposited by electron beam evaporation technique. Vacuum, 85(2), 214-220. http://dx.doi.org/10.1016/j.vacuum. 2010.05.017

Manifacier, J. C., Gasiot, J., \& Fillard, J. P. (1976). A simple method for the determination of the optical constants $\mathrm{n}, \mathrm{k}$ and the thickness of a weakly absorbing thin film. Journal of Physics E: Scientific Instruments, $9(11), 1002$. http://dx.doi.org/10.1088/0022-3735/9/11/032

McPhedran, R. C., Botten, L. C., McKenzie, D. R., \& Netterfield, R. P. (1984). Unambiguous determination of optical constants of absorbing films by reflectance and transmittance measurements. Applied optics, 23(8), 1197-1205. http://dx.doi.org/10.1364/AO.23.001197

Minkov, D. (1991). Computation of the optical constants of a thin dielectric layer on a transmitting substrate from the reflection spectrum at inclined incidence of light. JOSA A, 8(2), 306-310. http://dx.doi.org/10.1364/JOSAA.8.000306

Nilsson, P. O. (1968). Determination of optical constants from intensity measurements at normal incidence. Applied Optics, 7(3), 435-442. http://dx.doi.org/10.1364/AO.7.000435 
O’Hanlon, J. F. (2003). A User's Guide to Vacuum Technology. John Wiley \& Sons. Inc. http://dx.doi.org/10. $1002 / 0471467162$

Oliver, W. C., \& Pharr, G. M. (1992). An improved technique for determining hardness and elastic modulus using load and displacement sensing indentation experiments. Journal of materials research, 7(06), 1564-1583. http://dx.doi.org/10.1557/JMR.1992.1564

Pande, K. P., Nair, V. K. R., \& Gutierrez, D. (1983). Plasma enhanced metal - organic chemical vapor deposition of aluminum oxide dielectric film for device applications. Journal of applied physics, 54(9), 5436-5440. http://dx.doi.org/10.1063/1.332725

Patil, P. V., Bendale, D. M., Puri, R. K., \& Puri, V. (1996). Refractive index and adhesion of Al 2 O 3 thin films obtained from different processes - a comparative study. Thin solid films, 288(1), 120-124. http://dx.doi.org/10.1016/S0040-6090(96)08855-4

Pulker, H. K. (1984). Coatings on glass. North-Holland.

Segda, B. G., Jacquet, M., \& Besse, J. P. (2001). Elaboration, characterization and dielectric properties study of amorphous alumina thin films deposited by rf magnetron sputtering. Vacuum, 62(1), 27-38. http://dx.doi.org/10.1016/S0042-207X(01)00114-2

Thin Film Center Inc. (2015). Essential Macleod. Retrieved from http: // www.thinfilmcemter.com/

Vuoristo, P., Mäntylä, T., Kettunen, P., \& Lappalainen, R. (1991). Stoichiometry and impurities in sputtered alumina films on copper. Thin Solid Films, 204(2), 297-311. http://dx.doi.org/10.1016/0040-6090(91) 90071-5

Zhao, Y., Wang, Y., Gong, H., Shao, J., \& Fan, Z. (2003). Annealing effects on structure and laser-induced damage threshold of $\mathrm{Ta} 2 \mathrm{O} 5 / \mathrm{SiO} 2$ dielectric mirrors. Applied surface science, 210(3), 353-358. http://dx.doi.org/10.1016/S0169-4332(03)00153-3

Zhao, Z. W., Tay, B. K., Lau, S. P., \& Xiao, C. Y. (2003). Microstructural and optical properties of aluminum oxide thin films prepared by off-plane filtered cathodic vacuum arc system. Journal of Vacuum Science \& Technology A, 21(4), 906-910. http://dx.doi.org/10.1116/1.1577132

Zywitzki, O., Goedicke, K., \& Morgner, H. (2002). Structure and properties of Al 2 O 3 layers deposited by plasma activated electron beam evaporation. Surface and Coatings Technology, 151, 14-20. http://dx.doi.org/10.1016/S0257-8972(01)01632-2

\section{Copyrights}

Copyright for this article is retained by the author(s), with first publication rights granted to the journal.

This is an open-access article distributed under the terms and conditions of the Creative Commons Attribution license (http://creativecommons.org/licenses/by/3.0/). 